\title{
Acacia decurrens di Sebagian Kawasan Taman Nasional Gunung Merapi Yogyakarta
}

\author{
Sutomo $^{1}$ \\ ${ }^{1}$ Balai Konservasi Tumbuhan Kebun Raya “Eka Karya” Bali - LIPI, Candikuning, Baturiti, Tabanan, Bali, \\ 82191
}

Penulis untuk Korespondensi/E-mail: tommo.murdoch@gmail.com

\begin{abstract}
Abstrak- Acacia decurrens, adalah jenis asing yang mulai menjadi perhatian sejak dominasinya di lahan bekas erupsi Gunung Merapi tahun 2006. Tujuan dari kegiatan studi ini adalah untuk mendeskripsikan secara kuantitatif Ekologi Acacia decurrens, hubungannya dengan beberapa faktor lingkungan serta potensi keinvasifannya jika dikorelasikan dengan diversity index. Analisis vegetasi dilakukan di empat wilayah Taman Nasional Gunung Merapi (TNGM) yaitu Kalikining, Kaliadem, Plawangan dan Pranajiwa. Ordinasi menggunakan metode Non metric multidimensional scaling (NMDS) serta Canonical Corespondence (CCA) serta korelasi bivariate Spearman dilakukan dalam analisis data. Hasil analisis NMDS (2D stress $=0,14)$ memperlihatkan bahwa daerah terbuka akibat erupsi di Kaliadem kini didominasi oleh jenis $A$. decurrens. Hasil analisis juga menunjukkan adanya korelasi negatif yang signifikan (Spearman's rho $=0,6$ ) antara kelimpahan jenis $A$. decurrens dengan tingkat keanekaragaman jenis di dalam lokasi sampling. Dari hasil CCA, A. decurrens, pada tahap semai, nampak hidup berdampingan dengan jenis groundcover lainnya seperti Alangium javanicum, dan Araliaceae. Namun pada fase pohonnya, jenis ini cenderung membentuk tegakan murni. Acacia decurrens tingkat pohon nampaknya lebih memilih sites dengan tingkat $\mathrm{pH}$ yang lebih rendah sedangkan $A$. decurrens tingkat semai lebih banyak ditemui pada site-site ber $\mathrm{pH}$ lebih tinggi. $A$. decurrens berpotensi menjadi gulma di TNGM.
\end{abstract}

Abstract - Acacia decurrens, is an alien plant species that has begun to be a concern since its dominance in the former eruption of Mount Merapi in 2006. The purpose of this study is to describe quantitatively the Ecology of Acacia decurrens, its relation to several environmental factors and their invasive potential if correlated with diversity index. Vegetation analysis was carried out in four areas of Mount Merapi National Park, namely Kalikining, Kaliadem, Plawangan and Pranajiwa. Ordination using Non metric multidimensional scaling (NMDS) and Canonical Correspondence (CCA) methods and Spearman bivariate correlations were carried out in data analysis. NMDS analysis (2D stress $=0.14$ ) shows that open areas due to eruptions in Kaliadem are now dominated by A. decurrens. The results of the analysis also showed a significant negative correlation (Spearman's rho $=0.6$ ) between the abundance of $A$. decurrens species and the level of species diversity in the sampling location. From the results of CCA, A. decurrens, at the seedling stage, appears to coexist with other types of ground cover such as Alangium javanicum, and Araliaceae. But in the tree phase, this type tends to form pure stands and only occasionally appear alive can it coexist with other Fabaceae species such as Albizia lopantha. Acacia decurrens tree level seems to prefer sites with lower $\mathrm{pH}$ levels while A. decurrens seedling levels are more common at higher $\mathrm{pH}$ sites. A. decurrens have the potential to become weeds in the Mount Merapi National Park.

Keywords-Autekologi, Faktor Lingkungan, IAS, Risk Assesment

\section{PENDAHULUAN}

Enovember 2010 memberi dampak bagi lingkungan sekitar Gunung Merapi. Awan panas yang menyapu permukaan lereng gunung merupakan peristiwa abiotik yang mempengaruhi komponen biotik khususnya vegetasi. Secara alamiah apabila suatu kawasan vegetasi hutan mengalami bencana alam, maka lambat laun 
kawasan tersebut akan mampu mengadakan suksesi [1]. Proses pertumbuhan kembali vegetasi yang terkena bencana alam dapat berlangsung cepat atau lambat bergantung pada kerusakan yang ditimbulkan. Bencana letusan gunung berapi selain menimbulkan kerusakan dan kematian vegetasi juga dapat menciptakan kondisi yang sesuai bagi perkecambahan biji dan tumbuhnya permudaan pohon dan jenis berkayu lainnya [2]. Dalam hal ini, jenis asing dan jenis invasif adalah termasuk jenis yang dapat muncul setelah terjadinya gangguan habitat karena erupsi gunung berapi.

Beberapa contoh jenis asing yang telah menjadi jenis invasif dan menyebabkan gangguan terhadap habitat asli diantaranya adalah, Eichornia crassipes dan Lantana camara telah diintroduksikan sebagai tanaman hias, sekarang juga telah menjadi tumbuhan invasif yang sulit dikendalikan. Contoh invasi spesies asing yang hangat dibahas saat ini Acacia nilotica di Taman Nasional Baluran, Mertemiapeltata di Taman Nasional Bukit Barisan Selatan, dan Cissus sicyoides yang mengganggu tanaman koleksi di Kebun Raya Bogor, serta Ageratina riparia (Eupatorium riparium) yang mendominasi kawasan koleksi di Kebun Raya Bali. Invasi spesies asing diperburuk dengan kondisi perubahan iklim, menjadikannya sebagai ancaman serius terhadap biodiversitas dan tidak menutup kemungkinan memicu kepunahan suatu jenis asli.

Acacia decurrens, berasal dari Australia, adalah jenis tumbuhan berkayu yang sebenarnya diketahui mulai menjadi perhatian sejak dominasinya di lahan bekas erupsi Gunung Merapi tahun 2006 saat itu di Kaliadem, kawasan Taman Nasional Gunung Merapi (TNGM) yang berbatasan lansung dengan beberapa desa di sekitarnya. Paska erupsi Merapi pada tahun 2010 yang lalu, keberadaan jenis ini mulai mendapat perhatian serius karena merubah struktur dan komposisi jenis di kawasan terkena dampak erupsi, dari yang dahulu jenis penyusunnya beragam mulai Rasamala, Puspa, Casuarina, dan Pinus, kini menjadi tegakan murni A. decurrens.

Acacia decurrens memiliki sinonim Acacia mollisima Willd. Tumbuhan ini masuk dalam divisi spermatophyta, sub-divisi angiospermae, kelas dicotyledonae, bangsa resales, suku Fabaceae. Acacia memiliki tipe habitus berupa perdu, tinggi 3$8 \mathrm{~m}$.
Batangnya berkayu, bulat, bercabang, diameter 20$30 \mathrm{~cm}$, hijau. Daunnya majemuk, menyirip ganda, tersebar, tangkai panjang $\pm 1 \mathrm{~cm}$, hijau. Bunganya majemuk, bentuk malai, di ketiak daun, bulat, tangkai panjang $\pm 50 \mathrm{~mm}$, kuning. Buah berupa polong, majemuk, masih muda hijau setelah tua coklat kehitaman. Bijinya kecil, bulat, pipih, coklat kehitaman. Akar berupa akar tunggang, putih kotor.

Meskipun berbagai asumsi dan pendapat mengenai jenis ini mengenai status ekologi dan potensi keinvasifannya namun masih sangat kurang didukung dengan penelitian empiris di bidang ekologi. Untuk itu tujuan dari kegiatan studi ini adalah untuk mendeskripsikan secara kuantitatif Ekologi A. decurrens, hubungannya dengan beberapa faktor lingkungan serta potensi keinvasifannya jika dikorelasikan dengan diversity index.

\section{METODE PENELITIAN}

\section{Desain, tempat dan waktu}

Gunung Merapi terletak pada provinsi Yogyakarta dengan letak geografisnya adalah pada $7^{\circ} 32,5^{\prime} \mathrm{LS}$ dan $110^{\circ} 26,5^{\circ} \mathrm{BT}$. Kegiatan gunung api ini terekam dengan baik sejak tahun 1768. Gunung Merapi dikenal sebagai gunung api teraktif di dunia. Karakteristik erupsinya bersifat aktif permanen, yaitu guguran kubah lava atau lava pijar, membentuk aliran piroklastika (awan panas) atau 'nuee ardentes' yang dalam bahasa setempat dikenal dengan sebutan "wedhus gembel". Kejadian ini dipicu oleh tekanan dari dalam ataupun akibat gaya gravitasi yang bekerja pada kubah lava yang berada dalam posisi tidak stabil (pada dasar kawah lama yang miring) [3].

Penelitian dilaksanakan pada bulan AgutusSeptember 2013 di kawasan TNGM, Provinsi Yogyakarta. Kegiatan pengambilan data dilaksanakan pada lokasi yang terkena gangguan vulkanik pasca erupsi Merapi tahun 2010 yaitu di Kalikuning, Kaliadem serta di daerah Kaliurang (Bukit Plawangan dan Pranajiwa) sebagai kawasan yang tidak terkena gangguan vulkanik (Gambar 1). Identifikasi sampel dilakukan di Herbarium Kebun Raya Bali-LIPI di Bedugul. 


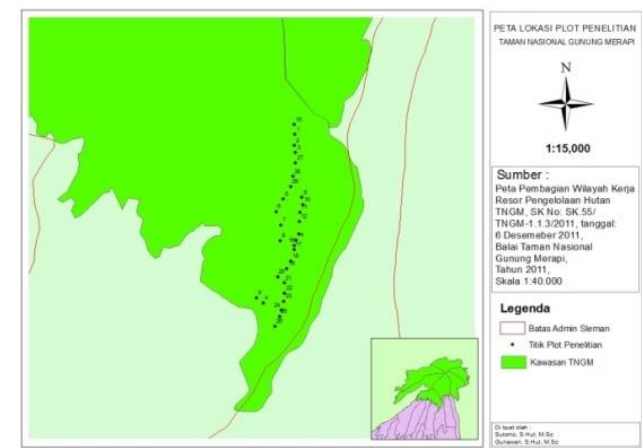

Gambar 1. Lokasi plot-plot sampling penelitian di kawasan Taman Nasional Gunung Merapi di Yogyakarta

\section{Jumlah dan cara pengambilan subjek}

Pengukuran faktor fisik lingkungan yang dilakukan yaitu kelembaban tanah (soil moisture \%), kadar keasaman tanah $(\mathrm{pH})$ serta ketinggian tempat (Altitude mdpl). Pengambilan data fisik dilakukan di setiap plot pengamatan.

\section{Jenis dan cara pengumpulan data}

Kelembaban tanah (soil moisture) dan kadar keasaman tanah $(\mathrm{pH})$ diukur dengan cara menancapkan soil tester ke dalam tanah sekitar $2 \mathrm{~cm}$ di setiap plot pengamatan. Sedangkan data ketinggian tempat (altitude) dilakukan pengecekan dengan alat altimeter yang terdapat di dalam perangkat GPS.

\section{Pengolahan dan Analisis data}

Keanekaragaman jenis tumbuhan dapat dihitung menggunakan indeks keanekaragaman ShannonWiener $\left(H^{\prime}\right)[4]$.

$$
\text { Shannon-Wiener }\left(\mathrm{H}^{\prime}\right) \quad: \mathrm{H}^{\prime}=-\sum_{i=1}^{S}\left(\frac{n i}{N}\right) \ln \left(\frac{n i}{N}\right)
$$

Keterangan:

$S$ : jumlah jenis

ni: jumlah jenis ke-i

$\mathrm{N}$ : jumlah individu semua jenis

Semakin besar nilai $\mathrm{H}^{\prime}$ menunjukkan semakin tinggi keanekaragaman jenis. Besarnya nilai keanekaragaman jenis Shannon-Wiener didefinisikan sebagai berikut:

1. $\mathrm{H}^{\prime}>3$ keanekaragaman jenis yang tinggi pada suatu kawasan.

$2.1 \leq \mathrm{H}^{\prime} \leq 3$ keanekaragaman jenis yang sedang pada suatu kawasan.

3. $\mathrm{H}^{\prime}<1$ keanekaragaman jenis yang rendah pada suatu kawasan.

Untuk mengetahui apakah dominasi jenis Acacia decurrens akan mempengaruhi keanekaragaman jenis lainnya, dilakukan analisis korelasi bivariate
Spearman antara kelimpahan Acacia decurrens dengan diversity index. Kemudian distribusi kelimpahan A. decurens tersebut di display secara ruang ordinasi dengan menggunakan analisis Non metric Multi dimensional Scaling (NMS) menggunakan software PRIMER ver.6 [5]. Sedangkan untuk mengetahui preferensi faktor lingkungan terukur apa yang lebih mempengaruhi keterdapatan atau keberadaan A. decurrens serta asosiasinya dengan jenis-jenis lain di suatu titik sampling plot di dalam loaksi studi areal TNGM digunakan Canonical Corespondence Analysis (CCA) [6][7] dengan menggunakan software CANOCO ver 4.5.

\section{HASIL DAN PEMBAHASAN}

Perubahan struktur lanskap apakah akibat bencana alam seperti letusan gunung berapi maupun faktor manusia berakibat terhadap kerusakan dan fragmentasi habitat. Fragmentasi habitat dianggap menjadi salah satu ancaman terbesar terhadap keanekaragaman hayati global [8]. Di dalam suatu habitat yang terfragmentasi akan terdapat munculnya fenomena efek tepi. Efek tepi, akan menyebabkan adanya peningkatan ketersediaan sumber daya yang berkaitan dengan iklim mikro yang kemudian akan menyebabkan meningkatnya kesempatan bagi jenis asing (eksotik) untuk menginvasi kawasan tersebut dan kemudian mendominasi dan merubah struktur dan komposisi spesies awal [9]. Hasil analisis NMDS (2D stress = $0,14)$ memperlihatkan bahwa daerah terbuka akibat erupsi di Kaliadem kini didominasi oleh jenis Acacia decurrens (Gambar 2). Jenis ini terlihat mulai memasuki areal di sekitarnya seperti sebagian Kalikuning, serta Pranajiwa (Gambar 2) meski dengan kelimpahan tidak sebesar kelimpahan $A$. decurrens di Kaliadem.

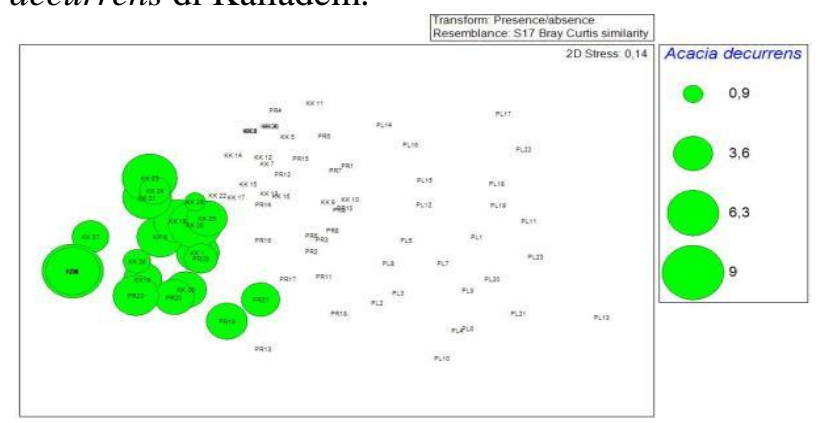

Gambar 2. Hasil ordinasi NMDS memperlihatkan distribusi dan kelimpahan Acacia decurrens pada plot di dalam lokasi sampling kawasan TNGM Yogyakarta. Keterangan PR = Pranajiwa, PL = Plawangan, KK = Kalikuning, KA = Kaliadem 
Komunitas yang lebih stabil memiliki keanekaragaman jenis lebih besar dibandingkan dengan keanekaragaman jenis pada komunitas yang sederhana [10]. Keanekaragaman jenis merupakan parameter yang sangat berguna untuk mempelajari pengaruh ganggguan terhadap faktor biotik serta untuk mengetahui tingkat suksesi dan kestabilan komunitas termasuk dalam hal invasi biologi jenis. Hasil penelitian di kawasan TNGM memperlihatkan adanya korelasi negatif yang signifikan (Spearman's rho $=0,6)$ antara kelimpahan jenis A. decurrens dengan tingkat keanekaragaman jenis di dalam lokasi sampling (Gambar 3). Kelimpahan jenis $A$. decurrens cenderung akan menyebabkan adanya penurunan keanekaragaman jenis. A. decurrens nampak berkompetisi dengan baik dengan jenisjenis tumbuhan lainnya, terutama jika terdapat tegakan jenis ini yang cukup rapat [11]. Di dalam tegakan rapat $A$. decurrens akumulasi atau penumpukan dari foliage daun yang luruh ke permukaan tanah akan membentuk lapisan tebal yang terakumulasi dan seiring waktu akan menghambat pertumbuhan jenis lainnya ataupun mengeliminir tumbuhnya vegetasi lainnya disekitarnya.

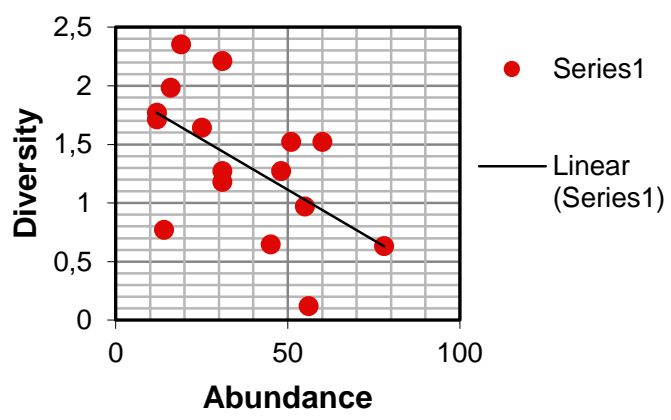

Gambar 3. Grafik korelasi antara kelimpahan (abundance) Acacia decurrens (sumbu X) dengan Indeks keanekaragaman tumbuhan (diversity) di lokasi sampling kawasan TNGM. Spearman's Rho $=-0.6$

Dari segi autekologi jenis, A. decurrens, pada tahap semai $(G)$, nampak hidup berdampingan dengan jenis groundcover lainnya seperti Alangium javanicum, dan Araliaceae (Gambar 4). Namun pada fase pohonnya $(T)$, jenis ini cenderung membentuk tegakan murni dan hanya sesekali nampak hidup dapat berdampingan dengan jenis Fabaceae lainnya seperti Albizia lopantha (Gambar 4). Acacia decurrens tingkat pohon nampaknya lebih memilih lokasi dengan tingkat $\mathrm{pH}$ yang lebih rendah sedangkan A.decurrens tingkat semai lebih banyak ditemui pada lokasi-lokasi ber $\mathrm{pH}$ lebih tinggi (Gambar 4).
Dikarenakan perbenihan yang mudah dari biji $A$. decurrens, dapat berpotensi menjadi gulma pada habitat dengan kondisi lingkungan yang menguntungkan bagi jenis tersebut. Meskipun jenis ini sudah ditanam secara luas sebagai tumbuhan ornamental di Hawaii, Selandia baru, Mediterania dan Eropa namun di Afrika Selatan jenis ini masuk sebagai invader kategori dua [12][13]. Acacia decurrens nampaknya berpotensi menjadi gulma di TNGM jika dilihat dari distribusinya yang dominan berupa tegakan murni serta kecenderungannya untuk menyebabkan penurunan tingkat keanekaragaman jenis di kawasan Taman Nasional. Untuk itu ke depannya tiap kegiatan termasuk upaya rehabiltasi lahan bekas erupsi dengan reintroduksi jenis baru yang sebelumnya tidak pernah ada di Lereng Merapi sebaiknya dilakukan penilaian risk assesment terlebih dahulu untuk mencegah terjadinya invasiveness suatu jenis terhadap jenis native maupun endemik di kawasan TNGM.

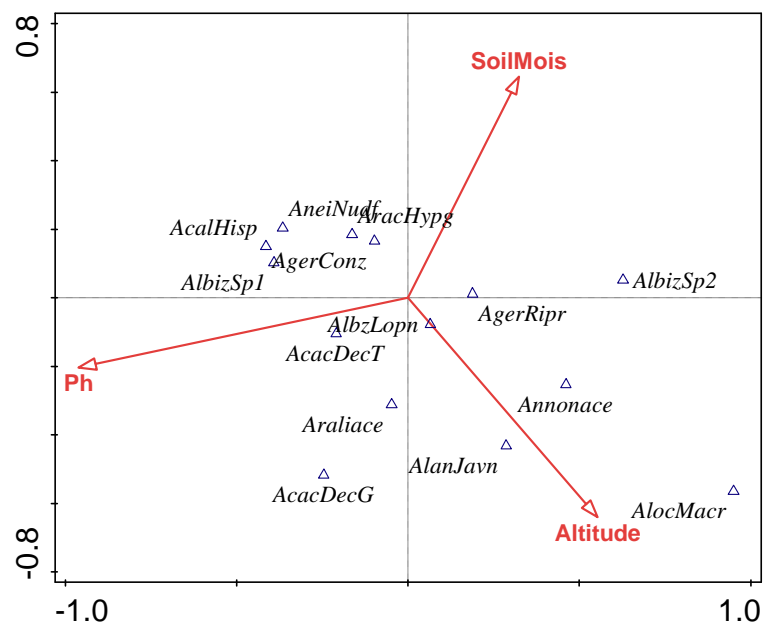

Gambar 4. Hasil analisis CCA memperlihatkan beberapa sumbu faktor lingkungan yang diukur serta distribusi beberapa jenis terpilih di dalam lokasi sampling kawasan Taman Nasional Gunung Merapi

\section{KESIMPULAN}

Acacia decurrens nampaknya berpotensi menjadi gulma di TNGM ika dilihat dari distribusinya yang dominan berupa tegakan murni serta kecenderungannya untuk menyebabkan penurunan tingkat keanekaragaman jenis di kawasan Taman Nasional. 


\section{UCAPAN TERIMA KASIH}

Terima kasih penulis untuk teknisi yang membantu di lapangan, I Ketut Sandi, rekan Gunawan dan Ni Kadek Erosi Undaharta. Penelitian ini terlaksana dengan bantuan the RUFFORD Foundation for conservation

https://www.rufford.org/projects/sutomo sutomo

\section{REFERENSI}

[1] Sutomo.Ecological succession on Mt Merapi and its implication for restoration.SEAMEOBIOTROP. 2013.

[2] Sutomo, J. R. Hobbs, \& V. A. Cramer, Plant community establishment on the volcanic deposit following nuees ardentes of Mount Merapi : diversity and floristic variation. Biodiversitas, 12(4), 86-91. 2011.

[3] J. M. Bardintzeff. Merapi Volcano (Java, Indonesia) and Merapi-type nuees ardentes. Bulletin Volcanology, 47. 1984.

[4] A. E., Magurran. Measuring Biological Diversity, USA, Blackwell Publishing company. 2004.

[5] K. R., Clarke, \& Gorley, R. N. PRIMER: Plymouth Routines In Multivariate Ecological Research. 6.0 ed. Plymouth: PRIMER-E Ltd. 2005.

[6] C., Ter Braak. Canonical correspondence analysis: A new eigenvector technique for multivariate direct gradient analysis. Ecology, 67, 1167-1179. 1986.
[7] C., Ter Braak, \& P. Smilauer,CANOCO for Windows version 4.5. 4.5 ed. Wageningen The Netherland: Biometrics Plant Research International. 2002.

[8] R. J. Hobbs, D. N. Cole, L. Yung, E. S. Zavaleta, G. H. Aplet, et al. Guiding concepts for park and wilderness stewardship in an era of global environmental change. Frontiers in Ecology and the Environment. 2009.

[9] B. J., Butterfield. Effects of facilitation on community stability and dynamics: synthesis and future directions. Journal of Ecology, 97, 1192-1201. 2009.

[10] Indriyanto. Ekologi Hutan, Jakarta, Penerbit Bumi Aksara. 2006.

[11] F., Ruskin. Mangium and other fast-growing acacias for the humid tropics. Innovations in tropical reforestation. National Academy Press, Washington. 1983.

[12] S., Henderson, Dawson, T. P. \& Whittaker, R. J. Progress in invasive plants research. Progress in Physical Geography, 30, 25-46. 2006.

[13] B. Walker, L. Stone, L. Henderson, \& M. Vernede, Size structure analysis of the dominant trees in a South African savanna. South African Journal of Botany, 52, 397-402. 1986. 